\title{
Antifungal activity of carvacrol and antifungal agent combinations against non-albicans Candida species
}

Atividade antifúngica do carvacrol e associação entre agentes antifúngicos contra espécies de Candida não-albicans

\author{
J. R. Nóbrega ${ }^{1, *}$; P. M. S. Sousa ${ }^{2}$; K. S. L. Mota ${ }^{3}$; L. V. Cordeiro ${ }^{1}$; F. P. Andrade \\ Júnior $^{1}$; W. A. Oliveira ${ }^{4}$ \\ ${ }^{1}$ Programa de Pós-Graduação em Produtos Naturais e Sintéticos Bioativos, Universidade Federal da Paraíba, 58033- \\ 455, João Pessoa, Paraíba, Brazil. \\ ${ }^{2}$ Acadêmica de Saúde, Centro de Educação e Saúde, Universidade Federal de Campina Grande, Sítio Olho D’água da \\ Bica, 58175-000, Cuité, Paraíba, Brazil. \\ ${ }^{3}$ Universidade Federal do Rio Grande do Norte, 59200-000, Santa Cruz, Rio Grande do Norte, Brazil. \\ ${ }^{4}$ Universidade Federal de Campina Grande, 58429-900, Cuité, Paraíba, Brazil
}

*jeffersonrodriguesn@hotmail.com

(Recebido em 13 de agosto de 2019; aceito em 29 de outubro de 2019)

\begin{abstract}
The aim of this study was to determine the minimum inhibitory concentration of carvacrol and to evaluate the antifungal activity of carvacrol when combinated with fluconazole, ketoconazole or amphotericin B against non-albicans Candida species. MICs were determined using microdilution method, and the combination study was conducted using the checkerboard method. The carvacrol MIC ranged between 128 and $512 \mu \mathrm{g} / \mathrm{mL}$. The greatest antifungal activity was displayed with ketoconazole. Conversely, fluconazole displayed the lowest activity. Amphotericin B showed MICs ranging from 0.5 to $2 \mu \mathrm{g} / \mathrm{mL}$. The best combinations were observed against Candida guilliermondii and Candida parapsilosis, which presented synergistic efects. Additive efect was observed in three combinations, whereas, indifferent interactions were seen in six combinations. No antagonistic effects were observed. Based on these results, we conclude that carvacrol retains high activity against non-albicans Candida strains, and the combinations between carvacrol and the antifungals tested yielded significant effects.
\end{abstract}

Keywords: antifungal, association, terpene.

O objetivo deste estudo foi determinar a concentração inibitória mínima de carvacrol e avaliar a atividade antifúngica desse fitoconstituinte quando combinado com fluconazol, cetoconazol ou anfotericina B contra espécies de Candida não-albicans. As CIMs foram determinadas usando o método de microdiluição, e o estudo da combinação foi conduzido usando o método de checkboard. A CIM carvacrol variou entre $128 \mathrm{e}$ $512 \mu \mathrm{g} / \mathrm{mL}$. A maior atividade antifúngica foi demonstrada com cetoconazol. Por outro lado, o fluconazol exibiu a menor atividade. A anfotericina B mostrou CIM variando de 0,5 a $2 \mu \mathrm{g} / \mathrm{mL}$. As melhores combinações foram observadas contra Candida guilliermondii e Candida parapsilosis, que apresentaram efeitos sinérgicos. Efeito aditivo foi observado em três combinações, enquanto, interações indiferentes foram vistas em seis combinações. Nenhum efeito antagônico foi observado. Com base nesses resultados, concluímos que o carvacrol retém alta atividade contra cepas de Candida não-albicans, e as combinações entre o carvacrol e os antifúngicos testados produziram efeitos significativos.

Palavras-chave: antifúngicos, associação, terpeno.

\section{INTRODUCTION}

The incidence and prevalence of fungal infections caused by species of Candida are increasing rapidly, especially in large populations of immunocompromised patients and/or those hospitalized with underlying grave diseases [1]. Candida spp. are considered opportunistic microorganisms present in the normal microbiota of the oral cavity, gastrointestinal tract and urogenital tract in humans. They can become pathogenic species when there is weakening of the host defense system through multiple risk factors [2]. Although $C$. albicans is the most prevalent species involved in invasive fungal infections, the incidence of infections caused by non-albicans species has increased significantly in recent years [3]. The high prevalence of non-albicans Candida species 
involvements may be a reflection of their inherently higher resistance levels to antifungals when compared to C. albicans [4].

These increases in micro-organism resistance and antifungal agent toxicity, as well as the lack of drugs available for the treatment of fungal infections have brought attention to the search for compounds with antimicrobial activities that arise mainly from natural products, which are more effective in treating these types of infections [5]. In this context, essential oils, which are complex mixtures of volatile compounds extracted from aromatic plants, are rich in terpenes; which, with their special structures are possibly the best of sources for obtaining a great variety of drugs [6]. Carvacrol (2-methyl-5-isopropylphenol) is a phenolic monoterpene present in the essential oils of many plants of the Lamiaceae, Euphorbiaceae, Verbenaceae and Poaceae families [7]. In relation to its biological activity: antinociceptive action [8], anti-inflammatory [9], antioxidant [10] and gastro-protective [11] activities have already been evidenced.

Rational combinations of antimicrobial substances may be an effective strategy for fighting infections caused by organisms insensitive to conventional therapies. Combination antimicrobial therapy looks to promote greater effectiveness in treatment, as well as permitting the use of lower concentrations of each drug. It can also increase the spectra of action, and thus prevent resistant organism development [12].

Considering the clinical importance of the infections caused by non-albicans species, and the necessity for the development of new antifungal drugs, the objective of this study was to investigate the antifungal activity of carvacrol both alone and in combination with fluconazole, ketoconazole, or amphotericin B against non-albicans Candida species strains.

\section{MATERIALS AND METHODS}

\subsection{Strains}

The following strains were used in this study: C. tropicalis (LM-10, ATCC 13803); C. guilliermondii (LM-103, LM-703); C. krusei (LM-120, LM-13) and C. parapsilosis (ATCC 20019, ATCC 22019). These strains were kindly provided by the collection of fungi cultures at the Mycology Laboratory of Paraíba Federal University, Brazil.

\subsection{Test substances}

The substances carvacrol, fluconazole, ketoconazole and amphotericin B were purchased from Sigma-Aldrich ${ }^{\circledR}$ (Steinheim, Germany). Culture media utilized were Sabouraud dextrose agar (SDA) from Difco Laboratories Ltd (Le Pont de Claix, France) and RPMI-1640-L-glutamine (without sodium bicarbonate) from Sigma-Aldrich (São Paulo, Brazil). Carvacrol and antifungals solutions were prepared at the time of the testing, these substances were first solubilized in $0,02 \%$ Tween 80 and $2 \%$ dimethyl sulfoxide [13]. They were then solubilized in sterile distilled water (q.s. $2 \mathrm{~mL}$ ) to give an initial concentration of $1,024 \mu \mathrm{g} / \mathrm{mL}$.

\subsection{Inoculum}

For inoculum preparations, cultures of Candida spp. were first grown in culture medium SDA (for $24-48 \mathrm{~h}$, at $37^{\circ} \mathrm{C}$ ). Subsequently, colonies from this culture were suspended in tubes containing sterile saline $(0.85 \%)$. These suspensions were then agitated and turbidities compared and adjusted to the $0.5 \mathrm{McF}$ arland scale, corresponding to an inoculum of approximately $10^{6} \mathrm{CFU} / \mathrm{mL}$ [14].

\subsection{Minimum inhibitory concentration (MIC)}

The MICs of carvacrol, fluconazole, ketoconazole and amphotericin B were determined using the broth microdilution method. MIC determinations for each substance were performed in 96-well microplates and using $100 \mu \mathrm{L}$ of RPMI-1640-L-glutamine (without sodium bicarbonate) as the culture. Each substance was serially diluted in proportions of two. Carvacrol concentrations were diluted from 1,024 to $2 \mu \mathrm{g} / \mathrm{mL}$, the antifungals were varied in concentrations of from 1,024 to 
$0.0625 \mu \mathrm{g} / \mathrm{mL}$. Then $10 \mu \mathrm{L}$ of the fungal suspension was added to each well. The plates were incubated at $37{ }^{\circ} \mathrm{C}$ and the reading was taken after $24 \mathrm{~h}$, noting the presence or absence of visible fungal growth [14]. The MIC was defined as the lowest concentration of carvacrol or antifungal agents capable of inhibiting visible fungal growth, as indicated by the color change in the colorless to pink cavities, indicating growth of the microorganism. Both negative controls (RPMI-1640-Lglutamine) and positive controls (RPMI-1640-L-glutamine and the micro-organism) were tested, to prove the sterility of the medium and the viability of the strains, respectively. Sensitivity controls (for DMSO and Tween 80) were also included in the studies. All tests were performed in triplicate.

\subsection{Checkerboard assay}

The study of combinations between carvacrol and the antifungal agents was conducted using checkerboard technique. Initially, $100 \mu \mathrm{L}$ of RPMI-1640-L-glutamine (without sodium bicarbonate) was distributed into the 96 wells of the micro-titer plate. Subsequently, $50 \mu \mathrm{L}$ of antifungal agent in various concentrations (MICx8, MICx4 MICx2, MIC, MIC/2 MIC/4 and $\mathrm{MIC} / 8$ ) were added in the vertical direction, and $50 \mu \mathrm{L}$ of carvacrol also in different concentrations (MICx8, MICx4 MICx2, MIC, MIC/2 MIC/4 and MIC/8) were added in the horizontal direction of the micro-titer plate. In this way, the various concentrations of carvacrol were tested in the presence of various concentrations of antifungal agent. Finally, we added $20 \mu \mathrm{L}$ of inoculum strains C. guilliermondii LM-103, C. tropicalis ATCC 13803, C. krusei LM-13 or C. parapsilosis ATCC 22019 each previously adjusted in accordance with the 0.5 McFarland scale. The plates were incubated at $37^{\circ} \mathrm{C}$ and readings taken after $24 \mathrm{~h}$ to observe the presence or absence of fungal visible growth, as indicated by the color change in the colorless to pink cavities, indicating growth of the microorganism [15]. All assays were performed in triplicate and controls tested.

The fractional inhibitory concentration (FIC) indexes were calculated, where FIC $_{\mathrm{A}}=\mathrm{MIC}$ of substance $\mathrm{A}$ (in combinations) / MIC of the substance A alone, and $\mathrm{FIC}_{\mathrm{B}}=\mathrm{MIC}$ of the substance B (in combinations) / MIC of the substance B alone. Subsequently, the fractional inhibitory concentration index (FICI) for each antifungal agent combinated with carvacrol was determined by summing FIC $_{\mathrm{A}}+\mathrm{FIC}_{\mathrm{B}}[16]$. The FICI was interpreted in the following way: synergism $\leq 0.5$; additivity $>0.5$ to $<1.0$; indifference $\geq 1$ and $<4$; or antagonism $\geq 4.0$ [17].

\section{RESULTS AND DISCUSSION}

The carvacrol MIC values against Candida species are shown in Table 1. The concentration of $512 \mu \mathrm{g} / \mathrm{mL}$ inhibited the growth of all strains, while $128 \mu \mathrm{g} / \mathrm{mL}$ was capable of inhibiting $50 \%$ of strains tested.

Table 1: Minimum inhibitory concentrations $(\mu \mathrm{g} / \mathrm{mL})$ of carvacrol against non-albicans Candida.

\begin{tabular}{lc}
\hline \multicolumn{1}{c}{ Strains } & Carvacrol \\
\hline C. tropicalis LM-10 & 128 \\
C. tropicalis ATCC 13803 & 128 \\
C. guilliermondii LM-103 & 512 \\
C. guilliermondii LM-703 & 256 \\
C. krusei LM-120 & 512 \\
C. krusei LM-13 & 256 \\
C. parapsilosis ATCC 20019 & 128 \\
C. parapsilosis ATCC 22019 & 128 \\
\hline
\end{tabular}

In accordance with the values proposed by Sartoratto et al. (2004) [18], values of MIC between $50-500 \mu \mathrm{g} / \mathrm{mL}$ are to be considered as high activity; values from $600-1,500 \mu \mathrm{g} / \mathrm{mL}$ as medium activity; and those above $1,500 \mu \mathrm{g} / \mathrm{mL}$ as low activity. In this study, the phytoconstituent showed 
high antifungal activity and it may be said that carvacrol was prominently revealed as a nonalbicans Candida species antifungal agent. The literature reports that the carvacrol has antibacterial activity against Porphyromonas gingivalis, Fusobacterium nucleatum and Streptoccus mutans (MIC $0.25 \%$ v/v) [19]. Activity was also demonstrated against fungi, among them: C. albicans (MIC $128 \mu \mathrm{g} / \mathrm{mL}$ ) [20], and also on 33 clinical isolates resistant to fluconazole, carvacrol yielded results (of between MIC 75 to $100 \mu \mathrm{g} / \mathrm{mL}$ ) for Candida spp. (C. albicans, C. tropicalis, C. glabrata, C. parapsilosis and C. krusei) [21]. Yet another study demonstrated carvacrol's activity against Aspergillus fumigatus, A. flavus (MIC $100 \mu \mathrm{g} / \mathrm{mL}$ ), Penicillium chrysogenum (MIC $125 \mu \mathrm{g} / \mathrm{mL}$ ) and against Rhizopus oryzae (MIC $200 \mu \mathrm{g} / \mathrm{mL}$ ) [22].

The antifungal MIC values (fluconazole, ketoconazole, and amphotericin B) against nonalbicans Candida species are shown in Table 2 . The antifungals showed varied activity patterns; the highest activity presented was that of ketoconazole, in contrast, fluconazole showed the lowest activity against the strains tested. Amphotericin B presented inhibition against $100 \%$ of the strains at the concentration of $2 \mu \mathrm{g} / \mathrm{mL}$. As for ketoconazole, the concentration of $0.5 \mu \mathrm{g} / \mathrm{mL}$ inhibited the growth of $50 \%$ of all isolates. To carry out individual evaluations of the antifungal agents and their activity against non-albicans Candida species, as well as for their achievements through combination with carvacrol, it was crucial to first determine their MICs.

Table 2: Minimum inhibitory concentrations $(\mu \mathrm{g} / \mathrm{mL})$ of antifungals against non-albicans Candida.

\begin{tabular}{lccc}
\hline \multicolumn{1}{c}{ Strains } & Fluconazole & Ketoconazole & Amphotericin B \\
\hline C. tropicalis LM-10 & 32 & 2 & 2 \\
C. tropicalis ATCC 13803 & 32 & 0.5 & 2 \\
C. guilliermondii LM-103 & 2 & 32 & 1 \\
C. guilliermondii LM-703 & 8 & 0.125 & 0.5 \\
C. krusei LM-120 & $*>1,024$ & 64 & 2 \\
C. krusei LM-13 & 256 & 0.5 & 2 \\
C. parapsilosis ATCC 20019 & 16 & 0.5 & 2 \\
C. parapsilosis ATCC 22019 & 16 & 0.5 & 2 \\
\hline *>: MIC was larger than the tested concentrations. & &
\end{tabular}

Confirming the results obtained in this study, Lima et al. (2013) [20] obtained MICs for amphotericin B against 16 strains of $C$. albicans of between 0.5 and $4 \mu \mathrm{g} / \mathrm{mL}$. Another study evaluated the activity of amphotericin B and fluconazole against non-albicans Candida isolates $(C$. tropicalis, C. krusei and C. parapsilosis), where the MICs ranged between 0.125 to $32 \mu \mathrm{g} / \mathrm{mL}$ [23].

The results from combinations against non-albicans Candida specie strains are shown in Table 3. Various forms of interaction between the terpene and the antifungals were observed, among them: synergism in $25 \%$ of the combinations, additivity in $25 \%$ and, finally indifferent for $50 \%$ of the combinations. However, no results were found to be antagonistic. When compared to the use of isolated antifungal medications, combinations between substances with promising antifungal properties can bring new mechanisms of action or intensify them, and possibly bring other benefits such as: decreasing adverse reactions, increasing the spectrum of action, capacity to treat resistant microorganisms, applications for differing infection types, providing treatment alternatives, or decreased toxicities [24]. 
Table 3. Minimum inhibitory concentration (combinations); fractional inhibitory concentration (FIC); and fraction inhibitory concentration index (FICI) of combination between carvacrol and antifungals against non-albicans Candida species.

\begin{tabular}{|c|c|c|c|c|}
\hline & \multicolumn{2}{|c|}{ FIC of compounds } & \multirow{2}{*}{ FICI } & \multirow{2}{*}{ Outcome } \\
\hline & Antifungals & Carvacrol & & \\
\hline \multicolumn{5}{|l|}{$\begin{array}{l}\text { C. guilliermondii } \\
\text { LM-103 }\end{array}$} \\
\hline Fluconazole & 0.06 & 1 & 1.06 & Indiference \\
\hline Ketoconazole & 0.125 & 0.125 & 0.25 & Synergism \\
\hline Amphotericin B & 0.125 & 0.125 & 0.25 & Synergism \\
\hline \multicolumn{5}{|l|}{$\begin{array}{l}\text { C. tropicalis } \\
\text { ATCC } 13803\end{array}$} \\
\hline Fluconazole & 1 & 0.25 & 1.25 & Indiference \\
\hline Ketoconazole & 0.5 & 0.125 & 0.625 & Additivity \\
\hline Amphotericin B & 0.125 & 1 & 1.125 & Indiference \\
\hline \multicolumn{5}{|l|}{ C. krusei LM-13 } \\
\hline Fluconazole & 0.5 & 0.125 & 0.625 & Additivity \\
\hline Ketoconazole & 0.125 & 1 & 1.125 & Indiference \\
\hline Amphotericin B & 0.125 & 1 & 1.125 & Indiference \\
\hline \multicolumn{5}{|l|}{$\begin{array}{l}\text { C. parapsilosis } \\
\text { ATCC } 22019\end{array}$} \\
\hline Fluconazole & 0.125 & 0.125 & 0.25 & Synergism \\
\hline Ketoconazole & 0.125 & 1 & 1.125 & Indiference \\
\hline Amphotericin B & 0.5 & 0.125 & 0.625 & Additivity \\
\hline
\end{tabular}

In a study conducted by Ahmad et al. (2013) [25] against both fluconazole -susceptible and resistant Candida spp., it was noted that $C$. tropicalis strains sensitive to the carvacrol/drug combination resulted in synergistic and additive effects. However, for the strains of $C$. tropicalis resistant to fluconazole, results for the combinations with the monoterpene were synergistic. For the fluconazole resistant species $C$. krusei, the results demonstrated were both additive and indifferent to the combinations presented. For $C$. parapsilosis, the combination between fluconazole and carvacrol achieved synergistic results.

\section{CONCLUSION}

This study has demonstrated the antifungal activity of carvacrol against non-albicans Candida species, a fact that is important because such information provides clearer expectations for future pharmacological studies; as to its toxicity, possible mechanisms of action, and its effectiveness for possible in vivo use. Testing of these combinations between the carvacrol and the chosen antifungal agents has led to the conclusion that some of these combinations promote synergistic effects. An important point to be considered is that antagonistic results were not found. However, applied studies in animal models, toxicological evaluations, and clinical studies are needed to generate solid evidence based data to support the use of such therapies. 


\section{ACKNOWLEDGEMENTS}

This research was supported by the Conselho Nacional de Desenvolvimento Científico e Tecnológico (CNPq).

\section{REFERENCES}

1. Kullberg BJ, Arendrup MC. Invasive candidiasis. N Engl J Med. 2015;373:1445-56.

2. Guinea J. Global trends in the distribution of Candida species causing candidemia. Clin Microbiol Infect. 2014;20(6):5-10. doi: 0.1111/1469-0691.12539

3. Deorukhkar SC, Saini S, Mathew S. Non-albicans Candida Infection: An Emerging threat. Interdiscip Perspect Infect Dis. 2014;1-7. doi:10.1155/2014/615958

4. Gonzalez GM, Elizondo M, Ayala J. Trends in species distribution and susceptibility of bloodstream isolates of Candida collected in Monterrey, Mexico, to seven antifungal agents: results of a 3-year (2004 to 2007) surveillance study. J Clin Microbiol. 2008;46(9):2902-5. doi: 10.1128 / JCM.00937-08.

5. Sardi JC, Scorzoni L, Bernardi T, Fusco-Almeida AM, Giannini MJS. Candida species: current epidemiology, pathogenicity, biofilm formation, natural antifungal products and new therapeutic options. J Med Microbiol. 2013;62(1):10-24. doi: 10.1099 / jmm.0.045054-0

6. Sardi JC, Almeida AM, Mendes-Giannini MJ. New antimicrobial therapies used against fungi present in subgingival sites-a brief review. Arch Oral Biol. 2011;56(10):951-9. doi: 10.1016/j.archoralbio.2011.03.007.

7. Krimer N, Başer KHC, Tümen G. Carvacrol rich plants in Turkey. Chem Nat Comp. 1995;31:37-42.

8. Melo FHC, Rios ERV, Rocha NFM, Citó MCO, Fernandes ML, Sousa DP, Vasconcelos SM, Sousa FC. Antinociceptive activity of carvacrol (5-isopropyl-2-methylphenol) in mice. J Pharm Pharmacol 2012;64(12):1722-9. doi: 10.1111 / j.2042-7158.2012.01552.x

9. Landa P, Kokoska L, Pribylova M, Vanek T, Marsik P. In vitro anti-inflammatory activity of carvacrol: inhibitory effect on cox-2 catalyzed prostaglandin E2 biosynthesis. Arch Pharm Res 2009;32(1):75-78. doi: 10.1007/s12272-009-1120-6

10. Beena N, Kumar D, Rawat DS. Synthesis and antioxidant activity of thymol and carvacrol based Schiff bases. Bioorg Med Chem Lett. 2013;23(3):641-45. doi:10.1016/j.bmcl.2012.12.001

11. Oliveira IS, Silva FV, Viana AF, Santos MR, Quintans-Júnior LJ, Martins MC, Nunes PH, Oliveira FDE, Oliveira RC. Gastroprotective activity of carvacrol on experimentally induced gastric lesions in rodents. Naunyn Schmied Arch Pharmacol. 2012;385(9):899-908. doi: 10.1007/s00210-012-0771-x.

12. Eliopoulos GM. Synergism and antagonism. Infect Dis Clin North Am. 1989;3:399-406.

13. Hood RJ, Wilkinson JM, Cavanagh MAH. Evaluation of common antibacterial screening methods utilized in essential oil research. J Essent Oil Res. 2003;15:428-433. doi:10.1080/10412905.2003.9698631

14. Clinical and Laboratory Standards Institute. CLSI document M27Ed4. 2017;37:1-30.

15. White RL, Burgess DS, Mandruru M, Bosso JA. Comparison of three different in vitro methods of detecting synergy: time-kill, checkerboard and E-test. Antimicrob. Agents Chemother. 1996;40(8):1914188.

16. Berenbaum MC. Synergy, additivism and antagonism in immunosuppression- a critical review. Clin Exp Immunol. 1977;28(1):1-18.

17. Lewis RE, Diekema DJ, Messer AS, Pfaller MA, Klepser ME. Comparison of Etest, chequerboard dilution and time-kill studies for the detection of synergy or antagonism between antifungal agents tested against Candida species. J Antimicrob Chemother. 2002;49(2):345-51. doi: 10.1093/jac/49.2.345.

18. Sartoratto A, Machado ALM, Delarmelina C, Figueira GM, Duarte MTC, Rehder VGL. Composition and antimicrobial activity of essential oils from aromatic plants used in Brazil. Braz J Microbiol. 2004;35(4):275-80. doi:10.1590/S1517-83822004000300001

19. Ciandrini B, Campana R, Federici S, Manti A, Battistelli M, Falcieri E, Papa S, Baffone W. In vitro activity of carvacrol against titanium-adherent oral biofilms and planktonic cultures. Clin Oral Investig. 2014;18(8):2001-13. doi: 10.1007/s00784-013-1179-9.

20. Lima IO, Pereira FO, Oliveira WA, Lima EO, Menezes EA, Cunha FA. Antifungal activity and mode of action of carvacrol against Candida albicans strains. J Essent Oil Res. 2013;25(2):1-6. doi:10.1080/10412905.2012.754728.

21. Ahmad A, Khan A, Aktar F, Yousuf S, Xess I, Khan LA, Manzoor N. Fungicidal activity of thymol and carvacrol by disrupting ergosterol biosynthesis and membrane integrity against Candida. Eur J Clin Microbiol Infect Dis. 2011;30(1):41-50. doi: 10.1007/s10096-010-1050-8 
22. Abbaszadeh S, Sharifzadeh A, Shokri H, Khosravi AR, Abbaszadeh A. Antifungal efficacy of thymol, carvacrol, eugenol and menthol as alternative agentes to control the growth of food-relevant fungi. J Mycol Med. 2014;24(2):51-6. doi: 10.1016/j.mycmed.2014.01.063

23. Pedroso RS, Menezes RP, Ferreira JC, Penatti MPA, Sá WM, Malvino LDS, Candido RC, Moreira TA. Antifungal susceptibility of isolates of Candida spp. by disk diffusion and broth microdilution. Biosci J. 2014;30(1):304-11.

24. Ferreira FG, Santos AD. Heteroresistance and fungi. Mycoses. 2017;60:562-8. doi:10.1111/myc.12639

25. Ahmad A, Khan A, Manzoor N. Reversal of efflux mediated antifungal resistance underlies synergistic activity of two monoterpenes with fluconazol. Eur J Pharm Sci. 2013;48(1-2):80-6. doi: 10.1016/j.ejps.2012.09.016. 